\title{
The mechanical control of nervous system development
}

\author{
Kristian Franze \\ Department of Physiology, Development and Neuroscience, University of \\ Cambridge \\ Correspondence: kf284@cam.ac.uk
}

Key words: mechanics, mechanosensitivity, mechanotaxis, mechanotransduction, stiffness, force, tension, brain folding 


\section{Summary}

The development of the nervous system has so far, to a large extent, been considered in the context of biochemistry, molecular biology, and genetics. However, there is growing evidence that many biological systems also integrate mechanical information when making decisions during differentiation, growth, proliferation, migration, and general function. Based on recent findings, I hypothesize that several steps during nervous system development rely on or are even driven by mechanical cues and forces, including neural progenitor cell differentiation, neuronal migration, axon extension, and the folding of the brain. 


\section{Introduction}

Many processes in development involve growth and motion at different length and time scales. All of these processes are driven by forces; the development of organisms and organ systems would not proceed without mechanics. For example, during neuronal development, neurons migrate and extend immature processes (neurites), which become axons and dendrites. Axons then grow in two different phases, both of which are distinguished by the nature of the forces that drive the growth. In the first phase, growth cones at the tips of axonal processes actively exert forces on their environment (Betz et al., 2011), thus pulling on the processes (Lamoureux et al., 1989). In a second phase, after connecting with their target tissue, axons may be passively pulled by the increasing distance between target and nervous tissue, resulting in considerable growth in length, a process referred to as stretch growth (Weiss, 1941). Once the final connectivity is established, tension may develop along neuronal axons, which may be involved in neuronal network formation and the folding of the brain. Apart from this direct requirement of forces for developmental processes, which has been studied to some degree in the past, the mechanical interaction of cells with their environment may add an additional level of control to several processes in the developing nervous system, including progenitor cell differentiation and cellular guidance.

The idea of an important contribution of mechanics to the development of the nervous system has been around for more than a century. However, the last decades have seen only little progress in this field when compared to other (e.g. electrophysiology, molecular biology, or genetics-based) areas of neuroscience. Progress often depends on the availability of appropriate methodology. Only recently has the increasing involvement of physical and engineering approaches in interdisciplinary studies of biological systems led to the development of new techniques and conceptual approaches that can be used to quantitatively probe and control relevant mechanical parameters such as cell and tissue stiffness, cellular forces, and tension. In recent years, such tissue mechanics-based studies have resulted in an increasing awareness of the importance of physical parameters, particularly in developmental biology, where cell systems constantly undergo dramatic rearrangements. These rearrangements naturally rely on forces acting on cells (without which there would be no motion) and the resistance of cells and cell groups to these forces, which depends on their viscoelastic properties and determines, for example, where cells are placed within a tissue. These fundamental and important parameters have so far been ignored to a large extent, but it is clear that a consideration of these parameters could provide a new understanding of developmental processes in general.

Here, I focus on the potential involvement of mechanics in the development of the nervous system.

\section{A brief overview of biomechanics and measurements}

The mechanical interactions between a cell and its environment depend on the forces acting on and exerted by the cell, the mechanical properties of the environment, and the coupling between the cell and its environment. Below, I highlight some mechanical features of cells and tissues, and I also explain how mechanical properties and forces can be measured.

\section{Cellular forces and tension}


Most if not all tissue cells, including neurons and glial cells, exert forces on their environment. Current techniques to determine cellular traction forces measure the strain $\gamma$ (i.e., deformation, see Glossary, Box 1) of a substrate of known compliance to calculate the stress $\sigma$ (i.e., force $F$ per contact area $A$, see Glossary, Box 1 ) exerted by cells (see Glossary, Box 1). These substrates are chosen to be linearly elastic (see Glossary, Box 1), which means that $\gamma \propto \sigma$. In contrast, many biological materials tend to be nonlinearly elastic (see Glossary, Box 1). In traction force microscopy (Munevar et al., 2001; Betz et al., 2011; Koch et al., 2012), a compliant substrate is deformed by cells and deformation fields are tracked using fluorescent nanoparticles embedded within the substrate. In an alternative approach, stiffer elastomeric substrates are structured as arrays of needle-like posts (Tan et al., 2003). Cells are cultured on these substrates and the deflection of the needle-like posts can be measured. At a smaller scale, intracellular forces can be measured using Förster resonance energy transfer (FRET)-based force sensors (Grashoff et al., 2010). Here, a short elastic domain is inserted between two fluorophores that undergo FRET; this tension sensor module is inserted into vinculin, a protein connecting the actin cytoskeleton with cell adhesion molecules (integrins). Since FRET efficiency decreases under tension, piconewton forces across vinculin can be measured.

In contrast to other cell types, neurons extend long processes, which are under mechanical tension (i.e., a pulling force, see Glossary, Box 1) (Bray, 1979; Heidemann and Buxbaum, 1994; Pfister et al., 2004; Siechen et al., 2009; Suter and Miller, 2011). This tension can be measured using calibrated microneedles: forces are applied to neurites, and the change in neurite length and the deflection of the needle are measured (Dennerll et al., 1988). At a larger scale, tissues in developing organisms are also under tension. This cortical tension can be measured using laser ablation, whereby a focused laser beam is used to cut a tissue, and the subsequent relaxation of the tissue is recorded and analyzed (Mayer et al., 2010).

\section{Measuring cell and tissue mechanics}

Biological cells and tissues are generally viscoelastic (see Glossary, Box 1), i.e., they behave partly like a viscous fluid (such as honey) and partly like an elastic solid (such as rubber, see Glossary, Box 1). As such, their response to an applied force depends on the time scale over which the force is applied: strain will increase with time if a stress is maintained until equilibrium is reached.

Most techniques that measure mechanical cell or tissue properties externally impose stress to the sample and then measure the resultant strain. The ratio of stress and strain $(\sigma / \gamma)$ yields an elastic modulus (see Glossary, Box 1 ), which is a measure of stiffness. If the stress is applied normal to the surface (i.e., tensile or compressive forces), the Young's modulus E (see Glossary, Box 1) is determined; if the stress is applied in parallel, the shear modulus $G$ (see Glossary, Box 1 ) is measured. In the simplest case, biological samples are assumed to be linear elastic materials, which is often a reasonable assumption for small deformations occurring over short time scales. However, more complex measurements also take different time scales into account and yield frequencydependent moduli that characterize both elastic and viscous properties.

There has been a flurry of different techniques developed to allow the measurement of cell mechanics and to allow mechanical manipulation of cells (summarized in Table 1), including atomic force microscopy (AFM), magnetic bead twisting, magnetic tweezers, optical traps, micropipette aspiration, cell poking, and 
microrheology. It should be noted that for non-contact, non-invasive methods (e.g. Brillouin microscopy or magnetic resonance elastography) the spatial resolution is currently not sufficient for studies at a cellular level. Importantly, almost all single cell mechanics methods are difficult, if not impossible, to carry out in situ.

Compliant substrates made of various hydrogels or rubbers as well as micropillar arrays have been used to mimic the mechanical properties of tissues in order to study mechanosensitive cell responses in vitro. To better represent the heterogeneous mechanical properties of biological tissues, stiffness gradients have been introduced to such surfaces using different approaches (Lo et al., 2000; Byfield et al., 2009; Kuo et al., 2012).

Finally, cells need to transmit their forces to their environment in order to move (and to probe the mechanical properties of the environment). This is done via adhesion complexes (point contacts in neurons, focal adhesions in glial cells), which couple the force generating cytoskeleton to the extracellular matrix or other cells. The adhesion strength of individual cells and growth cones can, for example, be quantified using calibrated microneedles (Zheng et al., 1994) and AFM (Krieg et al., 2008; Franze, 2011).

\section{Mechanical control of early neural development: regulation at the cellular and molecular level}

It has long been established that sensory neurons may respond to mechanical stimuli in their environment. Hearing, balance, touch, and proprioception are all mechanical senses, which are directly mediated by neurons. The majority of cells in the nervous system, however, are usually considered to rely on chemical signals only. Nevertheless, recent in vitro studies suggest that many neuronal as well as glial cell types also respond to mechanical cues throughout their development (reviewed in (Franze and Guck, 2010; Moore and Sheetz, 2011; Franze et al., 2013)).

The response of nervous tissue cells to mechanical stimuli is particularly interesting with respect to their mechanical environment. Adult nervous tissue is mechanically inhomogeneous (Elkin et al., 2007; Green et al., 2008; Christ et al., 2010) (for recent reviews on brain mechanics see (Chatelin et al., 2010; Franze and Guck, 2010; Franze et al., 2013)). Moreover, the stiffness of adult brain tissue changes with age (Sack et al., 2009), suggesting that already during development the mechanical properties of nervous tissue are prone to alteration, and cells encounter different mechanical cues depending on location and developmental stage.

\section{Neurogenesis}

The first event in the development of the nervous system to which mechanics could significantly contribute is the maturation of neural precursor cells. During cortical development, radial glial cells first give rise to neurons, and at later stages they differentiate into glial cells (Gotz and Huttner, 2005). Studies have shown that when mesenchymal stem cells are cultured on deformable substrates, compliant matrices, in contrast to stiffer substrates, promote differentiation into a neuronal phenotype (Engler et al., 2006; Keung et al., 2012) (Fig. 1). Brain tissue belongs to the softest tissues in our body, and it stiffens with age. While the mechanical properties of brain tissue were never measured at different developmental stages, it is conceivable that it starts stiffening already early during development, and at a certain developmental stage cortical tissue stiffness might exceed a critical threshold, thus contributing to the shift from neurogenesis to gliogenesis. 
In support of this hypothesis, on compliant substrates neuronal growth is promoted over that of glial cells (Georges et al., 2006). Furthermore, in reeler mice, which lack the extracellular matrix glycoprotein Reelin, an increase in the number of glial fibrillary acidic protein (GFAP)-positive astrocytes is accompanied by a decrease in the number of newly generated neurons (Zhao et al., 2007), and recently, it was shown that enhanced GFAP expression in retinal glial cells leads to their stiffening (Lu et al., 2010). The enhanced GFAP expression in the mouse mutants could thus lead to an increase in tissue stiffness that causes or at least contributes to the observed decrease in neurogenesis.

Apart from passive mechanical tissue properties, active forces (e.g. tension in the tissue) might also influence neuronal development. For example, the folding of the mammalian cortex, which itself is driven by forces (see below), leads to different tissue layer dimensions and mechanical stress distributions within the crowns and fundi of gyri (outward folds) (Bok, 1959; Welker, 1990; Xu et al., 2009). The differentiation of neuroblasts starts sooner in gyral crowns than in fundi, they increase sooner in size and shape, and the degree of elaboration of their dendrites is significantly more extensive (Welker, 1990), indicating that mechanical stress may be involved in progenitor cell development. In agreement with this hypothesis, mechanical tension in vitro drives neural stem cell differentiation towards mature neuronal cells (Chang et al., 2012).

\section{Neuron-glia interactions}

In contrast, the differentiation of Schwann cells and oligodendrocyte precursor cells, which are glial cells responsible for providing the myelin sheath for neurons, increases with stiffness (Cai et al., 2012; Jagielska et al., 2012). The interaction of neurons and glial cells, for example during myelin sheath or synapse formation, might therefore also be influenced by mechanical signaling: neurons, which usually grow well on soft substrates (Georges et al., 2006), are stiffer than their neighboring glial cells (Lu et al., 2006), which, on the other hand, seem to preferentially grow on stiffer substrates (Georges et al., 2006; Moshayedi et al., 2010). Astrocytes, for example, spread more on stiffer substrates, and their F-actin cytoskeleton is more organized compared to compliant surfaces (Georges et al., 2006; Moshayedi et al., 2010) (Fig. 1). The opposing mechanical properties and preferences of neurons and glial cell might attract them towards each other, and they might explain why neurons in mixed cultures often grow on top of glial cells.

\section{Neuronal migration and axonal growth}

In addition to well-established chemical signaling, the speed and direction of neuronal and growth cone migration (see also below) also depend on the mechanical interaction between cells and their environment. For example, mechanical tension along neurites has been suggested to contribute to the directionality of migrating neurons (Hanein et al., 2011).

The migration of fibroblasts (and few other non-neural cell types) was shown to be guided by stiffness gradients in their substrate ("mechanotaxis") in vitro (Lo et al., 2000). Neurons as well as growth cones during axonal pathfinding are likely to encounter environments with different mechanical properties as they migrate in situ. In support of this, stiffness gradients have been reported in CNS tissue recently (Elkin et al., 2007; Franze et al., 2011). Thus, although compelling evidence is still missing, it seems likely that neurons in the developing nervous system might be guided by mechanical signals, in addition to the battery of established chemical cues. 
After neurons have arrived at their destination, they send out immature processes. One of these processes turns into an axon, which usually grows over long distances, while the others become dendrites. Forces (tension) might not only be involved in the generation of axons (Bray, 1984). Many neuronal cell types adapt their morphology, and particularly the number, lengths and branching patterns of their neurites, to the stiffness of their substrate in vitro, including mammalian dorsal root ganglion cells, spinal cord and hippocampal, but not always cortical neurons (Georges et al., 2006; Jiang et al., 2008; Norman and Aranda-Espinoza, 2010; Koch et al., 2012). Neurite outgrowth is a mechanical process, and as such it might well be influenced by the interaction between neurites and the mechanical environment in vivo.

\section{Forces in growth cone motility}

Forces during neuronal growth are generated by growth cones, which are the leading tips of developing axons and dendrites. They are highly motile structures that determine the speed and direction of outgrowth. Growth cones are densely packed with actin filaments, which are polymerized at their leading edge. At the same time, myosin II motors, which are concentrated at the central zone of the growth cone, pull on actin filaments. These myosin-based forces, together with forces arising from actin polymerization, give rise to the well-studied retrograde actin flow observed in neurons (Medeiros et al., 2006). The actin cytoskeleton is also coupled to the substrate via point contacts, which are made up of protein complexes containing integrins, vinculin, talin, and many others (Renaudin et al., 1999). These point contacts form molecular 'clutches' (Suter and Forscher, 1998), which allow growth cones to transmit forces to their substrate, which may lead to its deformation (Franze et al., 2009; Betz et al., 2011; Koch et al., 2012). Accordingly, inhibition of actin polymerization leads to a reduction in the maximum force and velocity of growth cone protrusion, and a reduction in membrane stiffness results in larger forces and increased velocity (Amin et al., 2012). Thus, forces exerted by neurons can be controlled by controlling actin polymerization and myosin activity. Furthermore, interactions between actin filaments and microtubules, which modify stress distributions in the growth cone, are required for growth cone motility and turning (Geraldo and Gordon-Weeks, 2009). Growth cone traction forces finally oppose the tension that is acting along neurites (Bray, 1979; Dennerll et al., 1988; Heidemann and Buxbaum, 1994; Ayali, 2010; Suter and Miller, 2011) (see below). While the mechanisms of force application are comparatively well understood, how mechanical input is translated into an intracellular, biochemical response ("mechanotransduction") is currently ill-defined.

\section{Mechanics during neural circuit formation: tension in neuronal networks}

From the initiation of neurite growth, the establishment of synaptic connections with a target cell, to the formation of stable neuronal networks, neuronal processes are constantly under tension in vitro (Bray, 1979; Heidemann and Buxbaum, 1994) and in vivo (Gilmour et al., 2004; Siechen et al., 2009; Xu et al., 2010). Tension above or below a certain threshold stimulates neurite extension or retraction, respectively (Fig. 2) (Dennerll et al., 1989). For excellent recent reviews about neuronal tension see (Ayali, 2010) and (Suter and Miller, 2011). Such tensile forces are generated and maintained by the growth cone (Lamoureux et al., 1989; Lamoureux et al., 2010), the interaction of actin and myosin along the neurite (Dennerll et al., 1988), and by target cells pulling on the neurite (Weiss, 1941), and they are potentially involved in many different aspects of the development of the nervous system. 


\section{Towed growth and guidance of axons}

As mentioned above, the towing of axons results in tension, which is very likely to be crucially involved in the second phase of axonal growth (Weiss, 1941; Bray, 1984; Loverde et al., 2011). Pfister et al. showed that mechanical tension induces extreme "stretch growth" of integrated axon tracts at remarkable rates and extents $(8 \mathrm{~mm} / \mathrm{d})$ (Pfister et al., 2004), indicating that axonal lengthening is mainly limited by tension, or rather its relative absence.

Accordingly, when neurons are cultured on a flexible substrate, neurite extension significantly increases with increasing substrate stretching, and neurites preferentially align along the stretch direction (Chang et al., 2012). Similarly, muscle contractions in zebrafish generate mechanical forces that are required for proper pathfinding of sensory axons growing between the muscle and the skin of the fish (Paulus et al., 2009). Another example of the involvement of tension in axonal growth and guidance in vivo is exhibited by migrating primordium cells in the developing zebrafish, which not only tow axons of sensory neurons but also guide their pathfinding in this way (Gilmour et al., 2004).

\section{Network formation}

Tension along neurites also influences the shape of neuronal somata (Hanein et al., 2011) and the geometry of neurite branches in vitro (Bray, 1979; Shefi et al., 2004) and in vivo (Condron and Zinn, 1997). Differential tension along individual branches at a given junction particularly determines the angle between the branches and the branches' diameter. In a similar manner, tension may also influence the final morphology of neuronal networks. Once a neurite is connected to its target, tension promotes its stabilization while, at the same time, it causes retraction or elimination of collateral neurites (Anava et al., 2009). Thus, tension might serve as a signal for axonal and dendritic survival, and it might, vice versa, contribute to branch pruning (Franze et al., 2009). Accordingly, the orientation of apical dendrites of pyramidal neurons in the cortex and the degree of their dendritic and axonal arborization depends on their location relative to the curvature of the tissue (Welker, 1990), and thus likely on local tension (Xu et al., 2010). Finally, once the neuronal network is connected, the buildup of mechanical tension will lead to a shortening of the involved neuronal processes, thus contributing to the compactness of neural circuitry (Van Essen, 1997).

\section{Synapse formation and functioning}

Tension has also been suggested to contribute to synapse formation (Ayali, 2010). Recent evidence from in vivo experiments indicates that tension along axons can be actively regulated by neurons, and it is even involved in synapse functioning. Tension in Drosophila axons, for example, contributes to the clustering of neurotransmitter vesicles at presynaptic terminals at the neuromuscular junction (Siechen et al., 2009), and it modulates local and global vesicle dynamics (Ahmed et al., 2012). Hence, mechanical tension in and along neuronal axons might contribute not only to neuronal network formation but ultimately also in regulating neuronal function.

\section{Mechanical control at the macroscopic level: brain folding}

The folding of the mammalian cortex is the ultimate mechanical event in CNS development. Cortical folding abnormalities are found in several CNS disorder such as Williams syndrome, autism, and schizophrenia (Van Essen et al., 2006; Nordahl et al., 
2007; White and Hilgetag, 2011), indicating the importance of proper force distributions during CNS development.

The degree of cortical folding increases with brain size; the brains of larger animals are usually more convoluted. It is known that deeper cortical layers are thicker in convex gyri than in concave sulci (depressions in the surface of the brain) (Bok, 1959) (Fig. 3). Thus, to conserve the volume of the respective layers of gyri and sulci, neurons in different layers maintain their sizes and relative arrangements and rather adapt their shape, while glial cells and blood vessels maintain size and shape and change their relative arrangements. Although it is commonly accepted that intrinsic mechanical forces drive cortical folding, the origin of these forces is still disputed.

Numerous active and passive forces act in and on the cortex over different length and time scales. Sulci and fissures form only after all cortical neurons have been generated and after neuronal migration has been completed (Goldman-Rakic and Rakic, 1984), excluding these events as possible sources of the driving forces. Blood vessels, which run along sulci, can be excluded as well, as their alignment with the sulci occurs secondarily (Welker, 1990). Furthermore, cerebrospinal fluid shows no pressure differential between different brain regions (Welker, 1990), making its involvement unlikely. The skull is also not likely to impose mechanical constraints that are important for gyrification: its ossification starts only after the brain has stopped growing (Welker, 1990), and when different parts of the brain are removed during development, the remaining brain does not expand into the unoccupied regions of the cavity, while its fissuration is unaltered (Barron, 1950). While these insights disproved some of the older theories about cortical folding, currently there are still two major hypotheses to explain cortical folding (Fig. 3), as discussed below.

\section{Differential expansion hypothesis}

One hypothesis - the differential expansion hypothesis - assumes a central role for compressive forces arising from growth processes during cortical development. In this hypothesis, the tangential expansion of cortical regions, which is driven by the local augmented proliferation of cells and changes in cell sizes and shapes, is assumed to be the driving force for cerebral convolutional development (Mares and Lodin, 1970; Richman et al., 1975; Smart and McSherry, 1986; Ronan et al., 2013). Thus, forces driving brain folding are predominantly intracortical. In support of this hypothesis, the experimental reduction of proliferation in the outer subventricular zone leads to a reduction in cortical folding (Reillo et al., 2011). The application of finite element models confirmed that differential cortical growth together with remodeling of the subplate might explain cortical folding and the stress patterns found in brain tissue (Xu et al., 2010). Furthermore, it was shown that removal of the cerebral cortex affects the folding pattern of the remaining brain (Welker, 1990). In such early cortical ablations, gyri and sulci reorient towards the defect. In contrast, the aspiration of basal ganglia and the transection of all thalamocortical connections, does not change folding (Welker, 1990).

However, disruptions in neuronal proliferation do not always lead to loss of cortical convolutions; failure in cell division often results in smaller brains with preserved sulci and gyri (although on a smaller scale) (Neal et al., 2007). Furthermore, while lesions of the frontal lobe result in bilateral changes in sulcal patterns (Goldman and Galkin, 1978), lesions of the occipital lobe produce mainly asymmetric changes (Goldman-Rakic and Rakic, 1984). These differences are difficult to explain solely with local cellular proliferation in the cortex. An important difference between these regions are prominent callosal connections in the frontal lobe, which are absent in the primary 
visual areas. It is conceivable that forces could be transferred along these axons (between frontal lobes), suggesting that tension might be required for brain folding. An involvement of long-tract connectivity (intrahemispheric and callosal fibers innervating the cortical plate) in fissure formation would also explain how the disruption of a small part of the cortex results in widespread changes in fissuration of the entire cerebral surface of both hemispheres (Goldman-Rakic and Rakic, 1984).

\section{Tension hypothesis}

Tension along axons in the white matter has also been hypothesized to explain how the cortex folds (Van Essen, 1997). Strong cortico-cortical and weak corticosubcortical connections were suggested to result in outward folding, while the opposite scenario results in inward folding. Or in other words, more densely interconnected cortical areas tend to buckle together, thus forming a gyrus. An extension of this hypothesis has been suggested recently, taking into account species-specific differences in grey matter connectivity through the white matter (Herculano-Houzel et al., 2010). According to this model, cortical folding is not driven by the grey matter but by tension in the white matter. This idea was supported by morphological data showing the structure and connections of the prefrontal cortices (Hilgetag and Barbas, 2005).

However, recent microdissection assays revealed that, while axons in the developing brain are indeed under significant tension, the patterns of tissue stress are not consistent with the tension-based hypothesis. Tension exists along axons aligned radially inside the developing gyri and circumferentially in subcortical white matter tracts, but tension is not directed across the developing gyri (Xu et al., 2010). The observed relaxation after cutting was suggested to be attributable to enhanced growth in the grey matter compared to white matter (Xu et al., 2009).

In summary, there is currently no theory that can explain all experimental findings and observations relating to cortical folding. Most current approaches either favor the differential expansion or the tension hypothesis, but direct proof for either theory is still lacking. However, these two hypotheses are not mutually exclusive; both mechanisms are likely to contribute together to shaping the brain. Growth in one area of the grey matter could, for example, not only generate compression locally, but also tension on axons of neurons located within this area, which then transmit these forces and pull on a distant part of grey matter. Future experiments will reveal where, when and how local compression and tension along axons provide the forces that drive cortical folding.

\section{Mechanosensitivity and mechanotransduction}

While it is evident that forces and the mechanical properties of neuronal cells and their environment play a key role in the development of the nervous system, it remains unclear how these properties and forces are sensed and transduced by cells to give rise to the appropriate output.

The molecular basis of cell mechanosensitivity, in particular, is still poorly understood. Principally, every cellular element that is involved in transmitting forces to the environment is also exposed to the same forces. These forces across specific proteins can now be measured within cells with piconewton $(\mathrm{pN})$ sensitivity (Grashoff et al., 2010). Such forces will result in strain of the proteins (and membranes), which, if large enough, could cause conformational changes and be the first step in the mechanotransduction cascade. Possible candidates currently discussed as strain sensors include stretch-activated ion channels, caveolae, cryptic binding or phosphorylation sites, cell adhesion sites (including cell adhesion molecules (CAMs) 
such as integrins and cadherins, proteins linking CAMs to the cytoskeleton such as vinculin and talin, signaling proteins such as focal adhesion kinase (FAK), and adaptor proteins such as p130Cas), the cytoskeleton, and the nucleus itself (Fig. 4). Further possible key players in mechanotransduction include direct physical effects, motorclutch systems, tension-dependent exo- and endocytosis, and / or the activation of transcription factors. For recent reviews about mechanotransduction in developmental systems see (Wozniak and Chen, 2009; Zhang and Labouesse, 2012).

Mechanotransduction in neurons seems to involve a motor-clutch system (Chan and Odde, 2008), which couples the actin cytoskeleton to the substrate. Talin and vinculin, which link actin filaments to integrins and are involved in mechanotransduction (Margadant et al., 2011), are likely part of such clutches. During axon outgrowth, FAK is mechanically activated, which reinforces interactions between growth cones and the guidance cue netrin-1 (Moore et al., 2012). Netrin-1, in turn, positively regulates traction forces via Pak1-mediated shootin 1 phosphorylation, thus promoting actin-substrate coupling, force generation, and axon outgrowth (Toriyama et al., 2013). Finally, calcium influx through mechanosensitive ion channels, which also may affect talin, is involved in the neuronal response to mechanical stimuli (Franze et al., 2009; Kerstein et al., 2013).

It is likely that - similar to chemical signaling pathways - more than one mechanism is involved in cellular mechanotransduction. Furthermore, individual mechanical and chemical cues might activate similar or the same downstream signaling pathways and thus interact with each other. For example, when confronted with the chemical attractant netrin-1, advancing neuronal growth cones increased traction forces by an order of magnitude, resulting in redirecting the axon (Moore et al., 2009). Unraveling the molecular events that enable neurons and glial cells to detect and respond to mechanical stimuli will be key to understand the contribution of mechanical cues to the development of the nervous system.

Mechanics may even be directly involved in signal transduction. Phototransduction in microvillar photoreceptor cells of Drosophila, for example, is mediated by a $\mathrm{G}$ protein-activated phospholipase $\mathrm{C}$, which hydrolyses the membrane lipid PIP 2 (Hardie and Raghu, 2001). PIP 2 hydrolysis has recently been shown to alter the physical properties of the microvillar membrane, most likely increasing membrane tension and reducing crowding, which results in a contraction of the microvilli (Hardie and Franze, 2012). The light sensitive transient receptor potential (TRP) channels seem to respond to the mechanical forces generated by $\mathrm{PIP}_{2}$ hydrolysis rather than to chemical messengers, suggesting that mechanics is used as second messenger in metabotropic signal transduction (Hardie and Franze, 2012). TRP channels are also found in many different neurons and glial cells, and it is intriguing to speculate whether a similar, mechanical mechanism is involved in TRP channel activation in other parts of the nervous system. Such a mechanism could have tremendous impact on different aspects of the development of the nervous and other organ systems.

\section{Conclusions}

Many events during the development of the nervous system seem to be controlled by mechanics. Forces acting over different length and time scales drive motion and shape changes, and the cellular susceptibility to mechanical stimuli may be exploited as an additional level of control of developmental processes and a fundamental way of dealing with a changing environment. Understanding mechanics, which is very likely 
intimately linked to biochemistry, will thus be required to gain a more complete picture of development.

In recent years, technological progress has enabled the analysis and measurements of nervous tissue mechanics with ever increasing resolution, as well as first insight into neuronal and glial cell mechanosensitivity and mechanotransduction pathways. However, we are only beginning to understand when, where, and how mechanical processes take place in the nervous system in vivo. Recently developed mechanics techniques need to be combined with cutting edge biological tools to investigate the interplay of mechanics and biochemistry and to illuminate mechanotransduction in more detail. We also need new techniques that take in vitro studies a step further. For example, the mechanical 3D environment that cells encounter in vivo is currently difficult to reproduce in cell culture systems. Cell cultures with locally and reversibly tuneable mechanical properties would be a great asset to study cellular mechanosensitivity. Ultimately, mechanics measurements will have to be performed in vivo, which poses a big challenge.

Furthermore, we likely also need to go back and re-visit fundamental questions in nervous system development using newly developed techniques. For example, most textbooks still ascribe a mechanical function to glial cells: to provide structural support to neurons. However, using AFM, glial cells were shown to be twice as soft as their neighboring neurons (Lu et al., 2006), which should significantly limit the structural support they can offer. An involvement of mechanical signaling in neuronal development, migration and/or guidance, in signal transduction cascades, or neuronal network formation would revolutionize our understanding of the development of the nervous system.

\section{Acknowledgements}

I would like to thank all members of the K.F. laboratory, John Biggins, Dennis Bray, Kevin Chalut, James Fawcett, Nicole Franze, Jochen Guck, Bill Harris, Steve Heidemann, Claus Hilgetag, Christine Holt, Paul Janmey, Thora Karadottir, Kyle Miller, Andreas Reichenbach, Lisa Ronan, Jeff Urbach, and David van Essen for inspiring discussions about neuromechanics, and the UK Medical Research Council for financial support (Career Development Award). 


\section{References}

Ahmed, W. W., Li, T. C., Rubakhin, S. S., Chiba, A., Sweedler, J. V. and Saif, T. A. (2012) 'Mechanical tension modulates local and global vesicle dynamics in neurons', Cell Mol Bioeng 5(2): 155-164.

Amin, L., Ercolini, E., Shahapure, R., Migliorini, E. and Torre, V. (2012) 'The role of membrane stiffness and actin turnover on the force exerted by DRG lamellipodia', Biophys J 102(11): 2451-60.

Anava, S., Greenbaum, A., Ben Jacob, E., Hanein, Y. and Ayali, A. (2009) 'The regulative role of neurite mechanical tension in network development', Biophys J 96(4): 1661-70. Ayali, A. (2010) 'The function of mechanical tension in neuronal and network development', Integr Biol (Camb) 2(4): 178-82.

Barron, D. H. (1950) 'An Experimental Analysis of Some Factors Involved in the Development of the Fissure Pattern of the Cerebral Cortex', Journal of Experimental Zoology 113(3): 553-581.

Betz, T., Koch, D., Lu, Y. B., Franze, K. and Kas, J. A. (2011) 'Growth cones as soft and weak force generators', Proc Natl Acad Sci U S A 108(33): 13420-5.

Bok, S. T. (1959) Curvature of the Cerebral Cortex Histonomy of the cerebral cortex. Amsterdam Elsevier.

Bray, D. (1979) 'Mechanical tension produced by nerve cells in tissue culture', J Cell Sci 37: 391-410.

Bray, D. (1984) 'Axonal growth in response to experimentally applied mechanical tension', Dev Biol 102(2): 379-89.

Byfield, F. J., Wen, Q., Levental, I., Nordstrom, K., Arratia, P. E., Miller, R. T. and Janmey, P. A. (2009) 'Absence of filamin A prevents cells from responding to stiffness gradients on gels coated with collagen but not fibronectin', Biophys J 96(12): 5095-102.

Cai, L., Zhang, L., Dong, J. and Wang, S. (2012) 'Photocured biodegradable polymer substrates of varying stiffness and microgroove dimensions for promoting nerve cell guidance and differentiation', Langmuir 28(34): 12557-68.

Chan, C. E. and Odde, D. J. (2008) 'Traction dynamics of filopodia on compliant substrates', Science 322(5908): 1687-91.

Chang, Y. J., Tsai, C. J., Tseng, F. G., Chen, T. J. and Wang, T. W. (2012) 'Micropatterned stretching system for the investigation of mechanical tension on neural stem cells behavior', Nanomedicine.

Chatelin, S., Constantinesco, A. and Willinger, R. (2010) 'Fifty years of brain tissue mechanical testing: from in vitro to in vivo investigations', Biorheology 47(5-6): 255276.

Christ, A. F., Franze, K., Gautier, H., Moshayedi, P., Fawcett, J., Franklin, R. J., Karadottir, R. T. and Guck, J. (2010) 'Mechanical difference between white and gray matter in the rat cerebellum measured by scanning force microscopy', J Biomech 43(15): 2986-2992. Condron, B. G. and Zinn, K. (1997) 'Regulated neurite tension as a mechanism for determination of neuronal arbor geometries in vivo', Curr Biol 7(10): 813-6.

Dennerll, T. J., Joshi, H. C., Steel, V. L., Buxbaum, R. E. and Heidemann, S. R. (1988) 'Tension and compression in the cytoskeleton of PC-12 neurites. II: Quantitative measurements', J Cell Biol 107(2): 665-74.

Dennerll, T. J., Lamoureux, P., Buxbaum, R. E. and Heidemann, S. R. (1989) 'The cytomechanics of axonal elongation and retraction', J Cell Biol 109(6 Pt 1): 3073-83. Elkin, B. S., Azeloglu, E. U., Costa, K. D. and Morrison, B., 3rd (2007) 'Mechanical heterogeneity of the rat hippocampus measured by atomic force microscope indentation', J Neurotrauma 24(5): 812-22. 
Engler, A. J., Sen, S., Sweeney, H. L. and Discher, D. E. (2006) 'Matrix elasticity directs stem cell lineage specification', Cell 126(4): 677-89.

Franze, K. (2011) 'Atomic force microscopy and its contribution to understanding the development of the nervous system', Curr Opin Genet Dev 21(5): 530-7.

Franze, K., Francke, M., Günter, K., Christ, A. F., Körber, N., Reichenbach, A. and Guck, J. (2011) 'Spatial mapping of the mechanical properties of the living retina using scanning force microscopy', Soft Matter 7(7): 3147-3154.

Franze, K., Gerdelmann, J., Weick, M., Betz, T., Pawlizak, S., Lakadamyali, M., Bayer, J., Rillich, K., Gogler, M., Lu, Y. B. et al. (2009) 'Neurite branch retraction is caused by a threshold-dependent mechanical impact', Biophys J 97(7): 1883-90.

Franze, K. and Guck, J. (2010) 'The biophysics of neuronal growth', Rep Prog Phys 73(9): doi:10.1088/0034-4885/73/9/094601.

Franze, K., Janmey, P. and Guck, J. (2013) 'Mechanics in Neuronal Development and Repair', Annu Rev Biomed Eng: DOI: 10.1146/annurev-bioeng-071811-150045.

Georges, P. C., Miller, W. J., Meaney, D. F., Sawyer, E. S. and Janmey, P. A. (2006) 'Matrices with compliance comparable to that of brain tissue select neuronal over glial growth in mixed cortical cultures', Biophys J 90(8): 3012-8.

Geraldo, S. and Gordon-Weeks, P. R. (2009) 'Cytoskeletal dynamics in growth-cone steering', J Cell Sci 122(Pt 20): 3595-604.

Gilmour, D., Knaut, H., Maischein, H. M. and Nusslein-Volhard, C. (2004) 'Towing of sensory axons by their migrating target cells in vivo', Nat Neurosci 7(5): 491-2.

Goldman-Rakic, P. S. and Rakic, P. (1984) Experimental modification of gyral patterns. in N. Geschwind and A. Galaburda (eds.) Cerebral dominance. Cambridge (Massachusetts): Harvard University Press.

Goldman, P. S. and Galkin, T. W. (1978) 'Prenatal removal of frontal association cortex in the fetal rhesus monkey: anatomical and functional consequences in postnatal life', Brain Res 152(3): 451-85.

Gotz, M. and Huttner, W. B. (2005) 'The cell biology of neurogenesis', Nat Rev Mol Cell Biol 6(10): 777-88.

Grashoff, C., Hoffman, B. D., Brenner, M. D., Zhou, R., Parsons, M., Yang, M. T., McLean, M. A., Sligar, S. G., Chen, C. S., Ha, T. et al. (2010) 'Measuring mechanical tension across vinculin reveals regulation of focal adhesion dynamics', Nature 466(7303): 263-6. Green, M. A., Bilston, L. E. and Sinkus, R. (2008) 'In vivo brain viscoelastic properties measured by magnetic resonance elastography', NMR Biomed 21(7): 755-64. Hanein, Y., Tadmor, O., Anava, S. and Ayali, A. (2011) 'Neuronal soma migration is determined by neurite tension', Neuroscience 172: 572-9.

Hardie, R. C. and Franze, K. (2012) 'Photomechanical responses in Drosophila photoreceptors', Science 338(6104): 260-3.

Hardie, R. C. and Raghu, P. (2001) 'Visual transduction in Drosophila', Nature 413(6852): 186-93.

Heidemann, S. R. and Buxbaum, R. E. (1994) 'Mechanical tension as a regulator of axonal development', Neurotoxicology 15(1): 95-107.

Herculano-Houzel, S., Mota, B., Wong, P. and Kaas, J. H. (2010) 'Connectivity-driven white matter scaling and folding in primate cerebral cortex', Proc Natl Acad Sci U S A 107(44): 19008-13.

Hilgetag, C. C. and Barbas, H. (2005) 'Developmental mechanics of the primate cerebral cortex', Anat Embryol (Berl) 210(5-6): 411-7.

Jagielska, A., Norman, A. L., Whyte, G., Vliet, K. J., Guck, J. and Franklin, R. J. (2012)

'Mechanical environment modulates biological properties of oligodendrocyte progenitor cells', Stem Cells Dev 21(16): 2905-14. 
Jiang, F. X., Yurke, B., Firestein, B. L. and Langrana, N. A. (2008) 'Neurite outgrowth on a DNA crosslinked hydrogel with tunable stiffnesses', Annals of Biomedical Engineering 36(9): 1565-1579.

Kerstein, P. C., Jacques-Fricke, B. T., Rengifo, J., Mogen, B. J., Williams, J. C., Gottlieb, P. A., Sachs, F. and Gomez, T. M. (2013) 'Mechanosensitive TRPC1 channels promote calpain proteolysis of talin to regulate spinal axon outgrowth', J Neurosci 33(1): 273-85.

Keung, A. J., Asuri, P., Kumar, S. and Schaffer, D. V. (2012) 'Soft microenvironments promote the early neurogenic differentiation but not self-renewal of human pluripotent stem cells', Integr Biol (Camb) 4(9): 1049-58.

Koch, D., Rosoff, W. J., Jiang, J., Geller, H. M. and Urbach, J. S. (2012) 'Strength in the periphery: growth cone biomechanics and substrate rigidity response in peripheral and central nervous system neurons', Biophys J 102(3): 452-60.

Krieg, M., Arboleda-Estudillo, Y., Puech, P. H., Kafer, J., Graner, F., Muller, D. J. and Heisenberg, C. P. (2008) 'Tensile forces govern germ-layer organization in zebrafish', Nat Cell Biol 10(4): 429-36.

Kuo, C. H., Xian, J., Brenton, J. D., Franze, K. and Sivaniah, E. (2012) 'Complex stiffness gradient substrates for studying mechanotactic cell migration', Adv Mater 24(45): 605964.

Lamoureux, P., Buxbaum, R. E. and Heidemann, S. R. (1989) 'Direct evidence that growth cones pull', Nature 340(6229): 159-62.

Lamoureux, P., Heidemann, S. R., Martzke, N. R. and Miller, K. E. (2010) 'Growth and elongation within and along the axon', Dev Neurobiol 70(3): 135-49.

Lo, C. M., Wang, H. B., Dembo, M. and Wang, Y. L. (2000) 'Cell movement is guided by the rigidity of the substrate', Biophys J 79(1): 144-52.

Loverde, J. R., Tolentino, R. E. and Pfister, B. J. (2011) 'Axon stretch growth: the mechanotransduction of neuronal growth', J Vis $\operatorname{Exp}(54)$.

Lu, Y. B., Franze, K., Seifert, G., Steinhauser, C., Kirchhoff, F., Wolburg, H., Guck, J., Janmey, P., Wei, E. Q., Kas, J. et al. (2006) 'Viscoelastic properties of individual glial cells and neurons in the CNS', Proc Natl Acad Sci U S A 103(47): 17759-64.

Lu, Y. B., Iandiev, I., Hollborn, M., Korber, N., Ulbricht, E., Hirrlinger, P. G., Pannicke, T., Wei, E. Q., Bringmann, A., Wolburg, H. et al. (2010) 'Reactive glial cells: increased stiffness correlates with increased intermediate filament expression', Faseb J 25: 624631.

Mares, V. and Lodin, Z. (1970) 'The cellular kinetics of the developing mouse cerebellum. II. The function of the external granular layer in the process of gyrification', Brain Res 23(3): 343-52.

Margadant, F., Chew, L. L., Hu, X., Yu, H., Bate, N., Zhang, X. and Sheetz, M. (2011) 'Mechanotransduction In Vivo by Repeated Talin Stretch-Relaxation Events Depends upon Vinculin', PLoS Biol 9(12).

Mayer, M., Depken, M., Bois, J. S., Julicher, F. and Grill, S. W. (2010) 'Anisotropies in cortical tension reveal the physical basis of polarizing cortical flows', Nature 467(7315): 617-21.

Medeiros, N. A., Burnette, D. T. and Forscher, P. (2006) 'Myosin II functions in actinbundle turnover in neuronal growth cones', Nat Cell Biol 8(3): 215-26.

Moore, S. W., Biais, N. and Sheetz, M. P. (2009) 'Traction on immobilized netrin-1 is sufficient to reorient axons', Science 325(5937): 166.

Moore, S. W. and Sheetz, M. P. (2011) 'Biophysics of substrate interaction: influence on neural motility, differentiation, and repair', Dev Neurobiol 71(11): 1090-101.

Moore, S. W., Zhang, X., Lynch, C. D. and Sheetz, M. P. (2012) 'Netrin-1 attracts axons through FAK-dependent mechanotransduction', J Neurosci 32(34): 11574-85. 
Moshayedi, P., Costa, L. D., Christ, A., Lacour, S. P., Fawcett, J., Guck, J. and Franze, K. (2010) 'Mechanosensitivity of astrocytes on optimized polyacrylamide gels analyzed by quantitative morphometry', J Phys Condens Matter 22(19): doi: 10.1088/09538984/22/19/194114.

Munevar, S., Wang, Y. and Dembo, M. (2001) 'Traction force microscopy of migrating normal and H-ras transformed 3T3 fibroblasts', Biophys J 80(4): 1744-57.

Neal, J., Takahashi, M., Silva, M., Tiao, G., Walsh, C. A. and Sheen, V. L. (2007) 'Insights into the gyrification of developing ferret brain by magnetic resonance imaging', J Anat 210(1): 66-77.

Nordahl, C. W., Dierker, D., Mostafavi, I., Schumann, C. M., Rivera, S. M., Amaral, D. G. and Van Essen, D. C. (2007) 'Cortical folding abnormalities in autism revealed by surfacebased morphometry', J Neurosci 27(43): 11725-35.

Norman, L. L. and Aranda-Espinoza, H. (2010) 'Cortical Neuron Outgrowth is Insensitive to Substrate Stiffness', Cellular and Molecular Bioengineering 3(4): 398-414.

Paulus, J. D., Willer, G. B., Willer, J. R., Gregg, R. G. and Halloran, M. C. (2009) 'Muscle contractions guide rohon-beard peripheral sensory axons', J Neurosci 29(42): 13190201.

Pfister, B. J., Iwata, A., Meaney, D. F. and Smith, D. H. (2004) 'Extreme stretch growth of integrated axons', J Neurosci 24(36): 7978-83.

Reillo, I., de Juan Romero, C., Garcia-Cabezas, M. A. and Borrell, V. (2011) 'A role for intermediate radial glia in the tangential expansion of the mammalian cerebral cortex', Cereb Cortex 21(7): 1674-94.

Renaudin, A., Lehmann, M., Girault, J. and McKerracher, L. (1999) 'Organization of point contacts in neuronal growth cones', J Neurosci Res 55(4): 458-71.

Richman, D. P., Stewart, R. M., Hutchinson, J. W. and Caviness, V. S. (1975) 'Mechanical Model of Brain Convolutional Development', Science 189(4196): 18-21.

Ronan, L., Voets, N., Rua, C., Alexander-Bloch, A., Hough, M., Mackay, C., Crow, T. J., James, A., Giedd, J. N. and Fletcher, P. C. (2013) 'Differential Tangential Expansion as a Mechanism for Cortical Gyrification', Cereb Cortex.

Sack, I., Beierbach, B., Wuerfel, J., Klatt, D., Hamhaber, U., Papazoglou, S., Martus, P. and Braun, J. (2009) 'The impact of aging and gender on brain viscoelasticity', Neuroimage 46(3): 652-7.

Shefi, O., Harel, A., Chklovskii, D. B., Ben-Jacob, E. and Ayali, A. (2004) 'Biophysical constraints on neuronal branching', Neurocomputing 58-60: 487-495.

Siechen, S., Yang, S., Chiba, A. and Saif, T. (2009) 'Mechanical tension contributes to clustering of neurotransmitter vesicles at presynaptic terminals', Proc Natl Acad Sci US A 106(31): 12611-6.

Smart, I. H. and McSherry, G. M. (1986) 'Gyrus formation in the cerebral cortex of the ferret. II. Description of the internal histological changes', J Anat 147: 27-43.

Suter, D. M. and Forscher, P. (1998) 'An emerging link between cytoskeletal dynamics and cell adhesion molecules in growth cone guidance', Curr Opin Neurobiol 8(1): 106-16. Suter, D. M. and Miller, K. E. (2011) 'The emerging role of forces in axonal elongation', Prog Neurobiol 94(2): 91-101.

Tan, J. L., Tien, J., Pirone, D. M., Gray, D. S., Bhadriraju, K. and Chen, C. S. (2003) 'Cells lying on a bed of microneedles: an approach to isolate mechanical force', Proc Natl Acad Sci U S A 100(4): 1484-9.

Toriyama, M., Kozawa, S., Sakumura, Y. and Inagaki, N. (2013) 'Conversion of a Signal into Forces for Axon Outgrowth through Pak1-Mediated Shootin1 Phosphorylation', Current biology : CB 23(6): 529-534. 
Van Essen, D. C. (1997) 'A tension-based theory of morphogenesis and compact wiring in the central nervous system', Nature 385(6614): 313-8.

Van Essen, D. C., Dierker, D., Snyder, A. Z., Raichle, M. E., Reiss, A. L. and Korenberg, J. (2006) 'Symmetry of cortical folding abnormalities in Williams syndrome revealed by surface-based analyses', J Neurosci 26(20): 5470-83.

Weiss, P. (1941) 'Nerve patterns: The mechanics of nerve growth', Growth (Suppl Third Growth Symp) 5: 163-203.

Welker, W. (1990) Why Does Cerebral Cortex Fissure and Fold? in E. G. Jones and A. Peters (eds.) Cerebral Cortex. New York: Plenum Press.

White, T. and Hilgetag, C. C. (2011) 'Gyrification and neural connectivity in schizophrenia', Dev Psychopathol 23(1): 339-52.

Wozniak, M. A. and Chen, C. S. (2009) 'Mechanotransduction in development: a growing role for contractility', Nat Rev Mol Cell Biol 10(1): 34-43.

$\mathrm{Xu}, \mathrm{G}$., Bayly, P. V. and Taber, L. A. (2009) 'Residual stress in the adult mouse brain', Biomechanics and Modeling in Mechanobiology 8(4): 253-262.

Xu, G., Knutsen, A. K., Dikranian, K., Kroenke, C. D., Bayly, P. V. and Taber, L. A. (2010) 'Axons pull on the brain, but tension does not drive cortical folding', J Biomech Eng 132(7): 071013.

Zhang, H. and Labouesse, M. (2012) 'Signalling through mechanical inputs: a coordinated process', J Cell Sci 125(Pt 13): 3039-49.

Zhao, S., Chai, X. and Frotscher, M. (2007) 'Balance between neurogenesis and gliogenesis in the adult hippocampus: role for reelin', Dev Neurosci 29(1-2): 84-90.

Zheng, J., Buxbaum, R. E. and Heidemann, S. R. (1994) 'Measurements of growth cone adhesion to culture surfaces by micromanipulation', J Cell Biol 127(6 Pt 2): 2049-60. 


\section{Figures}

\section{Fig. 1: Mechanosensitivity of nervous tissue cells.}

(A, B) Only when mesenchymal stem cells are cultured on 'soft' neurogenic substrates with a compliance similar to that of brain tissue do they assume a neuronal phenotype and express the neuronal cytoskeletal marker $\beta 3$-tubulin (green). Scale bar: $5 \mu \mathrm{m}$. Nuclei are shown in blue. Adapted from (Engler et al., 2006) with permission from Elsevier. (C) When primary glial cells (astrocytes) are cultured on substrates with a stiffness comparable to that of muscle tissue ('stiff'), they spread and assume a morphology similar to that observed when they are cultured on tissue culture plastics. (D) However, when the same cells in the same chemical environment are cultured on softer substrates whose compliance is similar to that of brain tissue ('soft'), their cellular morphology changes drastically, and they extend star-like processes and resemble their in vivo appearance. Scale bar: $10 \mu \mathrm{m}$.

\section{Fig. 2: Tension along neuronal processes.}

(A) Neurites are under tension. (B) When they are pulled to one side with a microneedle, forces redistribute and, as a consequence, neurites change their direction of growth (C). (D) After removing the microneedle, initially relaxed neurites build up tension again, straighten, and resume growth away from the rest of the cell, changing direction again. Scale bar: $50 \mu \mathrm{m}$. Adapted from (Bray, 1979), permission pending. (E, F) Schematic drawing of force distributions in neurite extension. (E) Initially, the growth cone moves (black arrow) in a direction opposite to the tension acting along the neurite (red arrow). (F) When the neurite is deflected (grey arrow), the force redistributes and the neurite changes its outgrowth direction to again oppose the tension.

\section{Fig. 3: Forces in brain folding.}

During development of the brain, mechanical forces lead to the folding of the cortex. These forces are currently hypothesized to be either due to differential expansion (green arrows) of certain regions/cell types, or to tension (blue arrows) along neuronal axons (blue). As a consequence of the folding, the deeper cortical layers are thicker in gyri than in sulci. The volume of the cortex is maintained in the respective layers of gyri and sulci (indicated by lines crossing the layers). Image adapted from (Bok, 1959), permission pending.

\section{Fig. 4: Cellular mechanosensitivity.}

Every cellular element that is involved in transmitting forces is exposed to the same forces, resulting in strain that possibly can be detected and serve as first step in mechanotransduction. Possible strain sensors include stretch-activated ion channels, caveolae, cryptic binding or phosphorylation sites, cell adhesion/connection sites, the cytoskeleton, and the nucleus itself. Further possible key players in mechanotransduction include direct physical effects, motor-clutch systems, tensiondependent exo- and endocytosis, or the (slower) activation of transcription factors. 


\section{Figures}
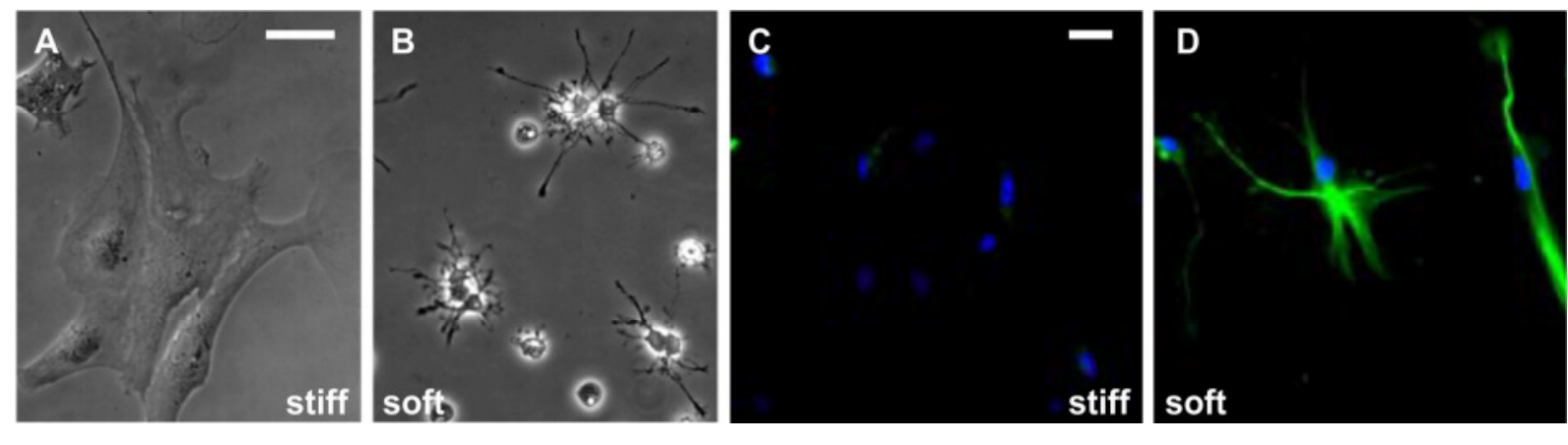

Fig. 1 
Developmental Neuromechanics

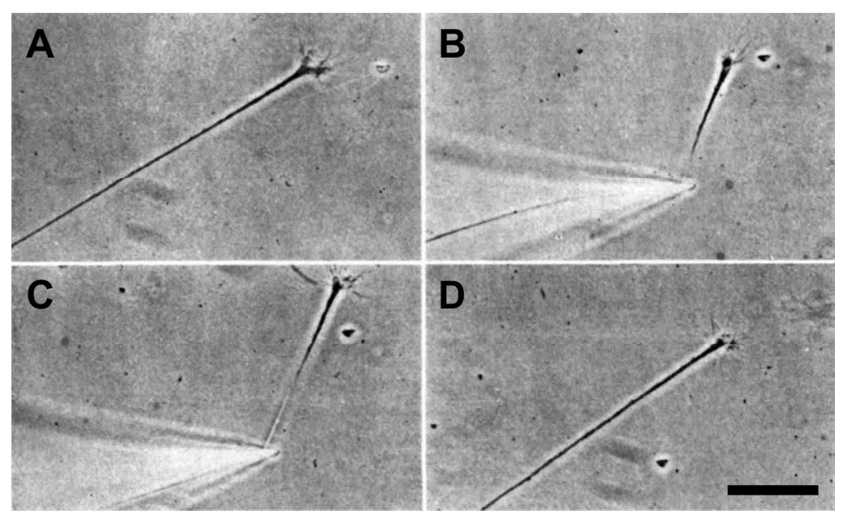

Fig. 2 


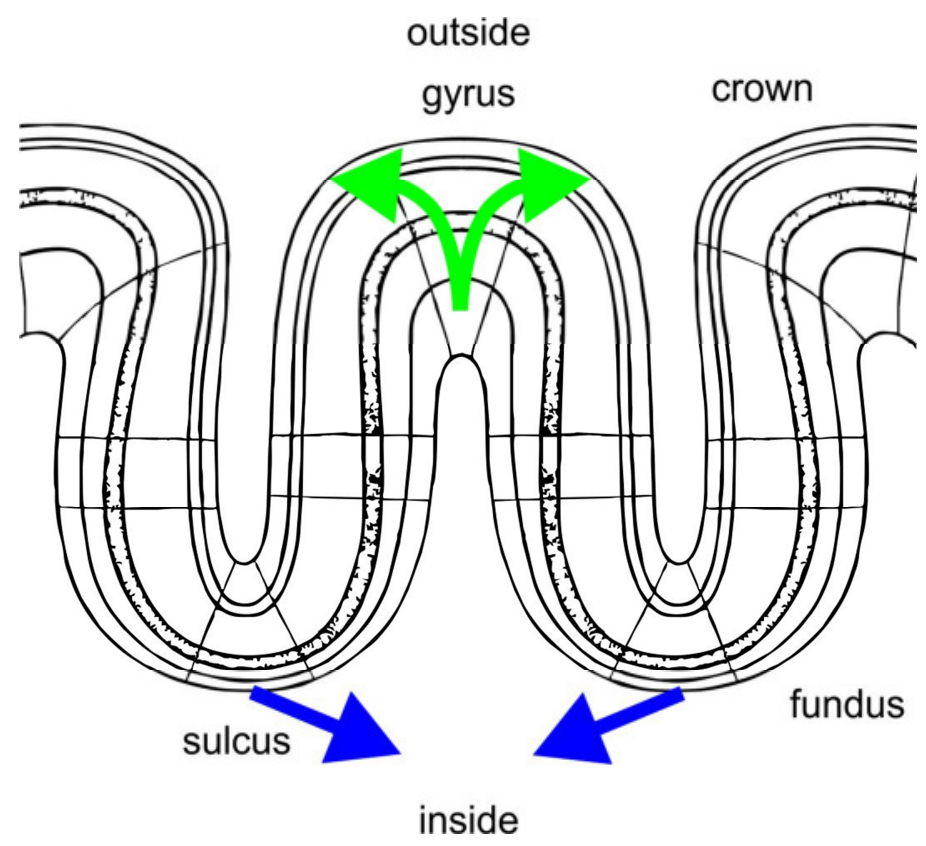

Fig. 3 
contractile forces

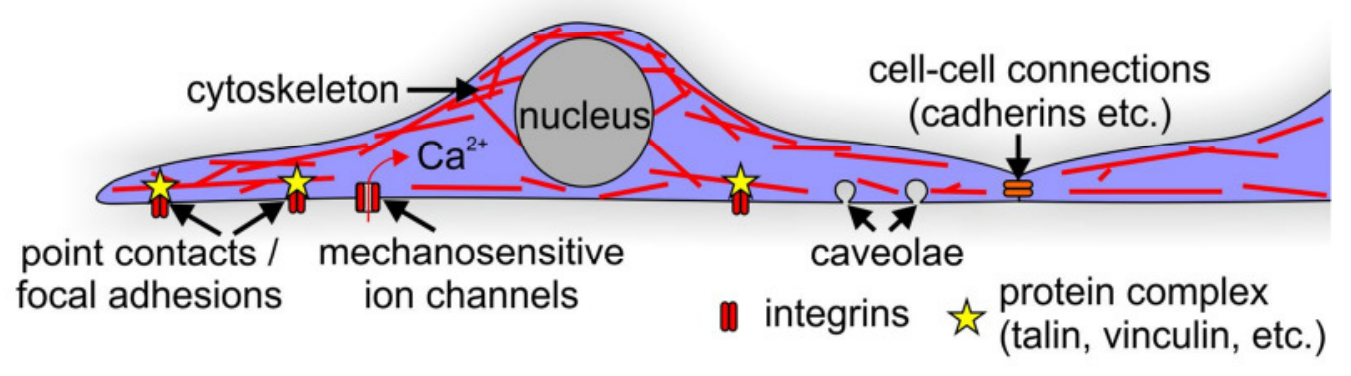

Fig. 4 


\section{Box 1: Terminology of mechanical parameters}

Elastic modulus: The ratio of stress $\sigma$ to strain $\gamma$; a constant describing a material's resistance to deformation. Unit: Pa.

Elasticity: The property of a material to deform in response to a force and to return to its original state once the force is removed.

Linear elasticity: Stress and strain are proportional; the elastic modulus is independent of the strain.

Non-linear elasticity: Biological materials usually show non-linear elasticity. Their elastic modulus changes with strain. Cytoskeletal and extracellular matrix networks, for example, stiffen when they are increasingly deformed.

Poisson's ratio ( $v$ ): Negative ratio of transverse to axial strain. For most materials, $0 \leq v \leq 0.5$. Biological materials often have a Poisson's ratio between 0.4 and 0.5 ; for incompressible materials such as water $v=0.5$.

Shear modulus $(G)$ : Quantifies the elastic resistance of a material to deformation in shear (stress is applied parallel to the surface). Unit: Pa. Can be transformed into Young's modulus via Poisson's ratio: $G=E /(2(1+v))$.

Strain $(\gamma)$ : Relative deformation of a material under stress. Dimensionless.

Stress $(\sigma)$ : The force exerted normalized by the area over which the force is applied. Unit: $\mathrm{Pa}\left(\mathrm{N} / \mathrm{m}^{2}=\mathrm{pN} / \mu \mathrm{m}^{2}\right)$. Depending on the direction of stress application: compressional, extension, or shear stress.

Tension: A pulling force (not a stress). Unit: $\mathrm{N}$.

Viscoelasticity: Combining viscous and elastic properties. Materials with viscoelastic properties partly recover their initial shape after stress application (elastic contribution) but also continue to flow (or increase strain; viscous contribution) as long as the stress is applied, until they either reach a plateau (viscoelastic solids) or slowly flow (or creep) without limit (viscoelastic liquids or viscoplastic materials). The viscoelastic response of a material to stress depends on the time scale.

Viscosity ( $\eta$ ): Resistance of a fluid to stress; the ratio of stress $\sigma$ to strain rate $d \gamma / d t$ (or flow rate). Unit: Pa•s.

Yield stress $\left(\sigma_{\mathrm{y}}\right)$ : Maximum stress that can be applied before a sample ruptures.

Young's modulus $(\boldsymbol{E})$ : Quantifies the elastic resistance of a material to elongation or compression (stress is applied normal to the surface). Unit: Pa. Can be transformed into shear modulus via Poisson's ratio: $E=2 G(1+v)$. 
Table 1: Cell mechanics measurement tools

\begin{tabular}{|c|c|c|c|c|}
\hline Technique & Forces & Main applications & Pros & Cons \\
\hline $\begin{array}{l}\text { Atomic force } \\
\text { microscopy } \\
\text { (AFM) }\end{array}$ & $\begin{array}{l}\mathrm{pN}-\mathrm{mN} \text {, } \\
\text { compressive } \\
\text { and tensile } \\
\text { forces }\end{array}$ & $\begin{array}{l}\text { molecular, cell, and } \\
\text { tissue stiffness } \\
\text { measurements, protein } \\
\text { unfolding, cell adhesion } \\
\text { measurements, stress } \\
\text { application to biological } \\
\text { samples, surface } \\
\text { scanning }\end{array}$ & $\begin{array}{l}\text { high spatial and } \\
\text { temporal } \\
\text { resolution, } \\
\text { combination } \\
\text { with other } \\
\text { techniques, } \\
\text { working range } \\
\text { over several } \\
\text { scales }\end{array}$ & $\begin{array}{l}\text { restricted to } \\
\text { surfaces, no } \\
\text { high } \\
\text { throughput }\end{array}$ \\
\hline Cell poking & $\begin{array}{l}\mathrm{nN}-\mu \mathrm{N}, \\
\text { compressive } \\
\text { forces }\end{array}$ & $\begin{array}{l}\text { cell stiffness } \\
\text { measurements }\end{array}$ & easy to set up & $\begin{array}{l}\text { restricted to } \\
\text { surfaces, } \\
\text { limited force } \\
\text { and spatial } \\
\text { resolution }\end{array}$ \\
\hline $\begin{array}{l}\text { Magnetic bead } \\
\text { twisting }\end{array}$ & $\begin{array}{l}\mathrm{pN}-\mathrm{nN} \\
\text { shear forces }\end{array}$ & $\begin{array}{l}\text { cell rheology, stress } \\
\text { application to cell } \\
\text { surface receptors }\end{array}$ & $\begin{array}{l}\text { high throughput, } \\
\text { good force } \\
\text { resolution }\end{array}$ & $\begin{array}{l}\text { restricted to } \\
\text { surfaces, } \\
\text { binding may } \\
\text { cause } \\
\text { secondary } \\
\text { effects }\end{array}$ \\
\hline $\begin{array}{l}\text { Magnetic } \\
\text { tweezers }\end{array}$ & $\begin{array}{l}\mathrm{pN}-\mathrm{nN}, \\
\text { tensile forces }\end{array}$ & $\begin{array}{l}\text { cell stiffness } \\
\text { measurements }\end{array}$ & easy to set up & $\begin{array}{l}\text { requires } \\
\text { magnetic } \\
\text { beads to be } \\
\text { taken up by or } \\
\text { bound to cells }\end{array}$ \\
\hline $\begin{array}{l}\text { Micropipette } \\
\text { aspiration }\end{array}$ & $\begin{array}{l}10 \mathrm{~s} \text { of } \mathrm{pN}- \\
\mu \mathrm{N} \text {, tensile } \\
\text { forces }\end{array}$ & $\begin{array}{l}\text { cell stiffness, } \\
\text { membrane tension } \\
\text { measurements }\end{array}$ & easy to set up & $\begin{array}{l}\text { limited spatial } \\
\text { and force } \\
\text { resolution }\end{array}$ \\
\hline Microrheology & $\begin{array}{l}\text { passive } \\
\text { method (no } \\
\text { forces } \\
\text { actively } \\
\text { applied) }\end{array}$ & cell rheology & $\begin{array}{l}\text { easy to set up, } \\
\text { high throughput, } \\
\text { in vivo } \\
\text { measurements } \\
\text { possible }\end{array}$ & $\begin{array}{l}\text { position of the } \\
\text { particles } \\
\text { difficult to } \\
\text { control }\end{array}$ \\
\hline $\begin{array}{l}\text { Optical } \\
\text { stretcher }\end{array}$ & $\begin{array}{l}\mathrm{pN} \text {, tensile } \\
\text { forces }\end{array}$ & cell deformation assays & $\begin{array}{l}\text { high throughput, } \\
\text { contact-free }\end{array}$ & $\begin{array}{l}\text { limited spatial } \\
\text { resolution and } \\
\text { force, heating } \\
\text { of the sample }\end{array}$ \\
\hline $\begin{array}{l}\text { Optical } \\
\text { tweezers }\end{array}$ & $\begin{array}{l}\mathrm{pN}, \text { tensile, } \\
\text { compressive, } \\
\text { shear forces }\end{array}$ & $\begin{array}{l}\text { stress application to } \\
\text { cells and molecules }\end{array}$ & $\begin{array}{l}\text { high temporal } \\
\text { and spatial } \\
\text { resolution }\end{array}$ & $\begin{array}{l}\text { limited force, } \\
\text { often } \mu \text { m sized } \\
\text { beads have to } \\
\text { be attached to } \\
\text { the sample, } \\
\text { heating }\end{array}$ \\
\hline
\end{tabular}

